\title{
Galerkin-Vlasov Method for Deflection Analysis of Isotropic Sandwich Plates under Uniform Load
}

\author{
Mama B.O. ${ }^{1}$, Ike C. C. ${ }^{2 *}$ \\ ${ }^{1}$ University of Nigeria, Nsukka, 410101 Enugu State, Nigeria; \\ ${ }^{2}$ Enugu State University of Science and Technology, P.M.B. 01660, Enugu, Nigeria
}

\section{Article info:}

Paper received:

The final version of the paper received:

Paper accepted online:
January 27, 2018

March 27, 2018

May 3, 2018
*Corresponding Author's Address:

charles.ike@esut.edu.ng

\begin{abstract}
In this work, the Galerkin-Vlasov method was used to solve the governing partial differential equation of equilibrium for isotropic sandwich plates with simply supported edges $(x= \pm a, y= \pm b)$ and under uniform load on the plate domain $(-a \leq x \leq a,-b \leq y \leq b)$. Vlasov procedure was adopted in choosing the displacement shape functions as orthogonal eigen functions of dynamic Euler Bernoulli beams with equivalent spans, simple supports and loading as the plate. The resulting Galerkin-Vlasov equation was solved to obtain the unknown generalised shape function. It was found that the deflections obtained were exact solutions to the problem of bending isotropic sandwich plates. The deflection was found to be made up of two components: flexural deformation and shear deformation.
\end{abstract}

Keywords: isotropic sandwich plate; Galerkin-Vlasov method; governing differential equation of equilibrium; orthogonal eigen functions; generalized displacements parameters.

\section{Introduction}

The idea of sandwich construction in the use of composite structures has become very popular due to the development of man-made cellular materials as core materials. Sandwich structures are composite structures made up of a pair of thin stiff, strong skins (called faces, facings or covers) a thick light weight core to separate the skins and carry loads from one skin to the other and an adhesive attachment capable of transmitting shear and axial loads to and from the core (Petras, 1998). Figures 1-2 show typical cross-sectional view and three dimensional view of a sandwich plate. Sandwich plates are plates made of three layers, the top and bottom layers (called facings) are usually thin and are made from high strength material while the thick middle layer (called core) is made from a relatively light and low strength material (MagnuckaBlandzi and Wittenborg, 2013). The motivation for use of sandwich plate as a structural material is two fold. First, in plate bending theory, the maximum normal stresses occur at the top and bottom surfaces. Hence it is sensible using high strength materials at the top and bottom and low and light weight materials in the middle. Second, the bending resistance for a plate is proportional to the value of the thickness. Thus, increasing the thickness by adding a core in the middle increases the flexural resistance. (Kormaniková and Mamuzic, 2011).
Due to the thick core, the use of the Kirchhoff (classical) plate theory results in an underestimation of the deflections since it does not account for the affect of the transverse shear deformation. The simplest shear deformable plate theories that takes cognizance of the transverse shear deformation effect are the Reissner and the Mindlin first order shear deformation plate theories.

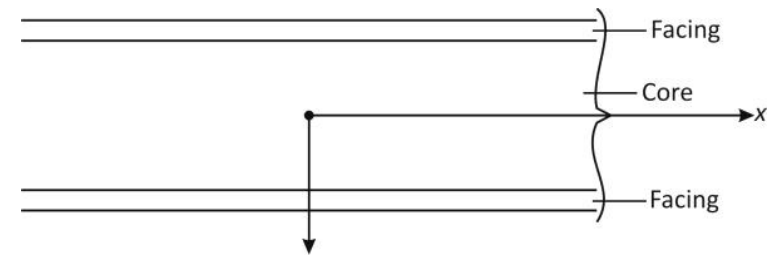

Figure 1 - Typical cross-sections of a sandwich plate

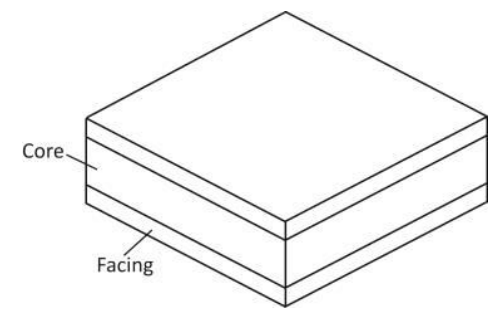

Figure $2-3 \mathrm{D}$ view of isotropic sandwich plate 
The maximum shear stress generally occurs in the middle of the sandwich plate, requiring a core to resist the shear.

The most commonly used sandwich plate theory is linear, and is an extension of the first order shear deformation plate theory. Linear sandwich plate theory is of vital importance in the analysis and design of sandwich panels which are frequently encountered in building construction, vehicle construction, airplane construction and refrigeration systems. (Liaw Boen Dar, 1965, Balken et al 2010). Some advantages of sandwich plates are (Allen, 1969; Vinson, 2001; Raville, 1955):

- sandwich plates have composite cross-sections with a considerably higher shear strength to weight ratio than the equivalent non composite plate. The composite plate also has a higher tensile strength to weight ratio;

- the high stiffness of the face sheet results in high bending strength to weight ratio for the composite plate.

The advantages in weight and bending stiffness make sandwich plates attractive in many applications.

Sandwich plates have found widespread application in the aircraft industry for both civil and military aircrafts, in the structure of missiles and satellites. Magnueka - Blandzi and Wittenbeek (2013) formulated equations for the mathematical model of a sandwich circular plate consisting of two facings and a core with variable mechanical properties. They derived their equation using the principle of total potential energy. Wang (1995) derived the governing equilibrium equations for sandwich plates on the basis of the Reissner-Mindlin shear deformation plate theory, and presented exact relationships between the deflections of isotropic sandwich plates and their corresponding Kirchhoff plates.

Kormenikova and Manuzic (2011) used the shear deformation plate laminate theory for sandwich plates by neglecting the membrane and bending deformations in the core and the shear deformation in the findings.

\section{Research Methodology}

\subsection{Theoretical framework}

The governing differential equation of equilibrium of rectangular sandwich plates can be obtained by ignoring the non linear terms in the Reissner's plate equation, (Liaw Boen Dar, 1968) thus,

$$
D \nabla^{2} \nabla^{2} w=p(x, y)-\frac{D}{D_{s}} \nabla^{2} p(x, y),
$$

where

$$
\begin{gathered}
D_{s}=h G_{c} \\
D=\frac{E h^{3}}{12\left(1-\mu^{2}\right)} \\
\nabla^{2}=\frac{\partial^{2}}{\partial x^{2}}+\frac{\partial^{2}}{\partial y^{2}}
\end{gathered}
$$

$$
\nabla^{4}=\nabla^{2} \nabla^{2}=\frac{\partial^{4}}{\partial x^{4}}+2 \frac{\partial^{4}}{\partial x^{2} \partial y^{2}}+\frac{\partial^{4}}{\partial y^{4}}
$$

$w(x, y)$ is the transverse displacement; $p$ is the distributed transverse load; $D_{s}$ is the shear modulus; $D$ is the flexural modulus.

Equation (1) can be expressed as:

$$
\begin{gathered}
\nabla^{4} w(x, y)=\frac{p(x, y)}{D}-\frac{1}{D_{s}} \nabla^{2} p(x, y) \\
\left(\frac{\partial^{4} w(x, y)}{\partial x^{4}}+2 \frac{\partial^{4}(w(x, y)}{\partial x^{2} \partial y^{2}}+\frac{\partial^{4} w(x, y)}{\partial y^{4}}\right)=\frac{p(x, y)}{D}-\frac{1}{D_{s}} \nabla^{2} p(x, y)
\end{gathered}
$$

\subsection{Methodology}

The rectangular sandwich plate $(2 a \times 2 b)$ shown in Figure 3 and subject to uniform transverse load $p_{0}$ on the entire domain was considered. The region of Cartesian coordinates was taken at the plate centre due to symmetry of the plate and the load.

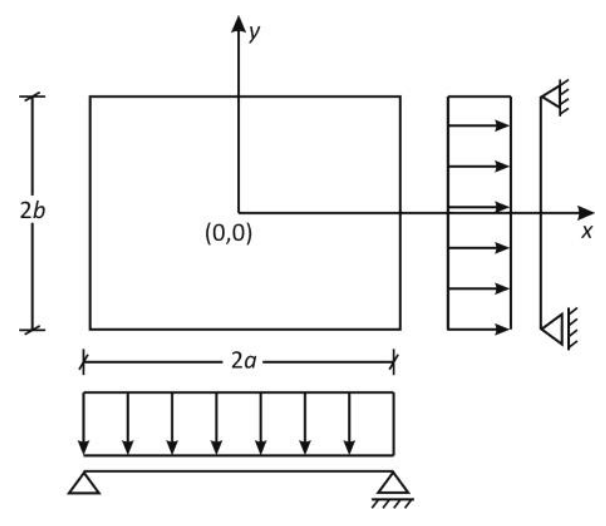

Figure 3 - Simply supported rectangular sandwich plate under uniformly distributed load

By the Galerkin-Vlasov variational method, $w(x, y)$ and $p(x, y)$ were considered as linear combinations of orthogonal eigen functions of vibrating simply supported Euler beams of spans $2 a$ and $2 b$ with simple supports at $x=-a ; x=a ; y=-b ; y=b$. The boundary conditions for the simply supported sandwich plates are:

$$
\begin{gathered}
w(x= \pm a, y)=0 ; \\
w_{x x}(x= \pm a, y)=\frac{\partial^{2} w}{\partial x^{2}}(x= \pm a, y)=0 ; \\
w(x, y= \pm b)=0 ; \\
w_{y y}(x, y= \pm b)=\frac{\partial^{2} w}{\partial y^{2}}(x, y= \pm b)=0 .
\end{gathered}
$$

By the Vlasov method, suitable shape functions chosen as the eigen functions of vibrating Euler-Bernoulli beams are found by applying Equations (8)-(11) on 


$$
w(x)=c_{1} \sin \alpha_{1} x+c_{2} \cos \beta_{1} x
$$

and

$$
\int_{-b}^{b} \int_{-a}^{a} F_{m}^{i v}(x) F_{m}(x) G_{n}^{2}(y) d x d y=I_{1} ;
$$

$$
w(y)=c_{3} \sin \alpha_{2} y+c_{4} \cos \beta_{2} y,
$$

where $c_{1}, c_{2}, c_{3}$ and $c_{4}$ are constants and $\alpha_{i}$ and $\beta_{i}$ are to be determined, $i=\{1 ; 2\}$.

Hence,

$$
\begin{aligned}
& F_{m}(x)=\cos \frac{m \pi x}{2 a}, m=\{1,3,5,7\} \\
& G_{n}(y)=\cos \frac{n \pi y}{2 b}, n=\{1,3,5,7\} .
\end{aligned}
$$

Following Kantorovich technique, $w(x, y)$ and $p(x, y)$ are considered as variable separable functions

$$
\begin{aligned}
w(x, y) & =\sum_{m}^{\infty} \sum_{n}^{\infty} w_{m n} F_{m}(x) G_{n}(y) ; \\
p(x, y) & =\sum_{m}^{\infty} \sum_{n}^{\infty} p_{m n} F_{m}(x) G_{n}(y) .
\end{aligned}
$$

The Galerkin - Vlasov variational integral becomes:

$$
\begin{aligned}
& \int_{-b}^{b} \int_{-a}^{a}\left\{\left(\frac{\partial^{4}}{\partial x^{4}}+2 \frac{\partial^{4}}{\partial x^{2} \partial y^{2}}+\frac{\partial^{4}}{\partial y^{4}}\right) \sum_{m}^{\infty} \sum_{n}^{\infty} w_{m n} F_{m}(x) G_{n}(y)-\frac{1}{D} \sum_{m}^{\infty} \sum_{n}^{\infty} p_{m n} F_{m}(x) G_{n}(y)\right. \\
& \left.+\frac{1}{D_{s}}\left(\frac{\partial^{2}}{\partial x^{2}}+\frac{\partial^{2}}{\partial y^{2}}\right) \sum_{m}^{\infty} \sum_{n}^{\infty} p_{m n} F_{m n} G_{n}\right\} F_{i}(x) G_{j}(y) d x d y=0 \\
& \text { Simplifying, } \\
& \sum_{m}^{\infty} \sum_{n}^{\infty} w_{m n} \int_{-b}^{b} \int_{-a}^{a}\left(\frac{\partial^{4}}{\partial x^{4}}+2 \frac{\partial^{4}}{\partial x^{2} \partial y^{2}}+\frac{\partial^{4}}{\partial y^{4}}\right) F_{m}(y) G_{n}(y) F_{i}(x) G_{j}(y) d x x y=\sum_{m}^{\infty} \sum_{n}^{\infty} \frac{p_{m n}}{D} \int_{-b}^{b} \int_{-a}^{a} F_{m}(x) \\
& w_{m n}=\frac{\frac{p_{m n}}{D} I_{4}}{\left(I_{1}+2 I_{2}+I_{3}\right)}-\frac{\frac{p_{m n}}{D_{s}}\left(I_{5}+I_{6}\right)}{\left(I_{1}+2 I_{2}+I_{3}\right)} ; \\
& w_{m n}=w_{m n}^{(f)}+w_{m n}^{(s)}=\frac{p_{m n}}{D}\left(\frac{I_{4}}{I_{1}+2 I_{2}+I_{3}}\right)-\frac{p_{m n}}{D_{s}}\left(\frac{I_{5}+I_{6}}{I_{1}+2 I_{2}+I_{3}}\right)
\end{aligned}
$$$$
\times G_{n}(y) F_{i}(x) G_{j}(y) d x d y-\sum_{m}^{\infty} \sum_{n}^{\infty} \frac{p_{m n}}{D_{s}} \int_{-b}^{b} \int_{-a}^{a}\left(\frac{\partial^{2}}{\partial x^{2}}+\frac{\partial^{2}}{\partial y^{2}}\right) F_{m}(x) G_{n}(y) F_{i}(x) G_{j}(y) d x d y
$$

Simplification yields for particular integer values of $m$ and $n$,

$$
\begin{gathered}
w_{m n} \int_{-b}^{b} \int_{-a}^{a}\left(F_{m}^{i v}(x) G_{n}(y) F_{i}(x) G_{j}(y)+2 F_{m}^{\prime \prime}(x) G_{n}(y) F_{i}(x) G_{j}(y)+F_{m}(x) G_{n}^{i v}(y) F_{i}(x) G_{j}(y)\right) d x d y \\
=p_{m n} \int_{-b}^{b} \int_{-a}^{a} F_{m}(x) G_{n}(j) F_{i}(x) G_{j}(y) d x d y-\frac{p_{m n}}{D_{s}} \int_{-b}^{b} \int_{-a}^{a}\left(F_{m}^{\prime \prime}(x) G_{n}(y) G_{i}(x) G_{j}(y)\right.
\end{gathered}
$$

$$
\left.+F_{m}(x) G_{n}^{\prime \prime}(y) F_{i}(x) G_{j}(y)\right) d x d y .
$$

The orthogonality properties of the integrals of the eigen functions $F_{m}(x)$ and $G_{n}(y)$ lead to the simplification of the Galerkin - Vlasov variational integral to obtain:

$$
\begin{gathered}
w_{m n} \int_{-b}^{b} \int_{-a}^{a}\left(F_{m}^{i v}(x) F_{m}(x) G_{n}^{2}(y)+2 F_{m}^{\prime \prime}(x) F_{m}(x) G_{n}^{\prime \prime}(y) G_{n}(y)+F_{m}^{2}(x) G_{n}^{i v}(y) G_{n}(y)\right) d x d y \\
=\frac{p_{m n}}{D} \int_{-b}^{n} \int_{-a}^{a} F_{m}^{2}(x) G_{n}^{2}(y) d x d y \\
-\frac{p_{m n}}{D_{s}} \int_{-b}^{b} \int_{-a}^{a}\left(F_{m}^{\prime \prime}(x) F_{m}(x) G_{n}^{2}(y)+F_{m}^{2}(x) G_{n}^{\prime \prime}(y) G_{n}(y)\right) d x d y
\end{gathered}
$$

Let

$$
\int_{-b}^{b} \int_{-a}^{a} F_{m}^{\prime \prime}(x) F_{m}(x) G_{n}^{\prime \prime}(y) G_{n}(y) d x d y=I_{2} ;
$$

$$
\int_{-b}^{b} \int_{-a}^{a} F_{m}^{2}(x) G_{n}^{i v}(y) G_{n}(y) d x d y=I_{3} ;
$$

$$
\int_{-b}^{b} \int_{-a}^{a} F_{m}^{2}(x) G_{n}^{2}(y) d x d y=I_{4} ;
$$

$$
\int_{-b}^{b} \int_{-a}^{a} F_{m}^{\prime \prime}(x) F_{m}(x) G_{n}^{2}(y) d x d y=I_{5} ;
$$

$$
\int_{-b}^{b} \int_{-a}^{a} F_{m}^{2}(x) G_{n}^{\prime \prime}(y) G_{n}(y) d x d y=I_{6} .
$$

Then

$$
w_{m n}\left(I_{1}+2 I_{2}+I_{3}\right)=\frac{p_{m n}}{D} I_{4}-\frac{p_{m n}}{D_{s}}\left(I_{5}+I_{6}\right) ;
$$

Using the Wolfram Mathematica integration software,

$$
\begin{gathered}
I_{1}=\frac{m^{4} \pi^{4}}{16 a^{4}} a b=\left(\frac{m \pi}{2 a}\right)^{4} a b ; \\
I_{2}=-\left(\frac{m \pi}{2 a}\right)^{2} a-\left(\frac{n \pi}{2 b}\right)^{2} b=\frac{n^{2} m^{2} \pi^{4}}{16 a^{2} b^{2}} a b ; \\
I_{3}=\frac{n^{4} \pi^{4}}{16 b^{4}} b a ; \\
I_{4}=a b ; \\
I_{5}=-b a \frac{m^{2} \pi^{2}}{4 a^{2}} ; \\
I_{6}=-b a \frac{n^{2} \pi^{2}}{4 b^{2}} .
\end{gathered}
$$

For uniformly distributed transverse load of intensity $p_{0}$ over the entire plate domain,

$$
p_{m n}=\frac{16 p_{0}}{m n \pi^{2}}(-1)^{\left(\frac{m+n-2}{2}\right)} .
$$

Using the integrals, and Equation (37), we obtain 


$$
\begin{aligned}
w^{f}=\sum_{m}^{\infty} \sum_{n}^{\infty} \frac{256 p_{0}(-1)^{(m+n-2) / 2}}{D \pi^{6}\left(m n\left(\frac{m^{2}}{a^{2}}+\frac{n^{2}}{b^{2}}\right)^{2}\right)} \cos \frac{m \pi x}{2 a} \cos \frac{n \pi y}{2 b} \\
w^{s}(x, y)=\sum_{m}^{\infty} \sum_{n}^{\infty} \frac{64 p_{0}(-1)^{(m+n-2) / 2}}{D_{s} \pi^{4}\left(m n\left(\frac{m^{2}}{a^{2}}+\frac{n^{2}}{b^{2}}\right)\right)} \cos \frac{m \pi x}{2 a} \cos \frac{n \pi y}{2 b}
\end{aligned}
$$

\subsection{Maximum deflection}

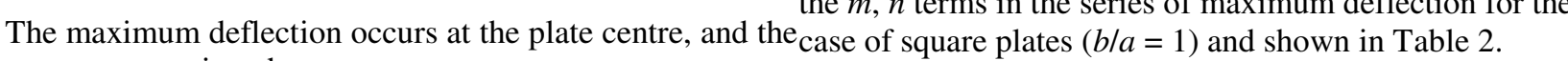
components are given by:

$w_{\max }^{(f)}=\sum_{m}^{\infty} \sum_{n}^{\infty} \frac{256 p_{0}(-1)^{(m+n-2) / 2}}{D \pi^{6}\left(m n\left(\frac{m^{2}}{a^{2}}+\frac{n^{2}}{b^{2}}\right)^{2}\right)}=\frac{256 p_{0}}{D \pi^{6}} \sum_{m}^{\infty} \sum_{n}^{\infty} \frac{(-1)^{(m+n-2) / 2}}{m n\left(\frac{m^{2}}{a^{2}}+\frac{n^{2}}{b^{2}}\right)^{2}}$

$$
w_{\max }^{(s)}=\frac{64 p_{0}}{D_{s} \pi^{4}} \sum_{m}^{\infty} \sum_{n}^{\infty} \frac{(-1)^{(m+n-2) / 2}}{m n\left(\frac{m^{2}}{a^{2}}+\frac{n^{2}}{b^{2}}\right)} .
$$

The values of maximum deflection for the flexural and shear components are calculated for various values of aspect ratio, and presented in Table 1 for various ratios of $D / D_{s}$. The convergence properties of the deflation functions Equations (37)-(38) are illustrated by considering the $m, n$ terms in the series of maximum deflection for the

Table 1 - Maximum deflection coefficients for the centre of uniformly loaded sandwich plates $(2 a \times 2 b)$ with simply supported edges $(x= \pm a ; y= \pm b)$

\begin{tabular}{|c|c|c|c|c|c|c|}
\hline$b / a$ & $w_{\max }^{(f)}\left(\times \frac{p_{0} a^{4}}{D}\right)$ & $w_{\max }^{(s)}\left(\times \frac{p_{0} a^{2}}{D_{s}}\right)$ & $\begin{array}{c}\frac{D_{s} a^{2}}{D}=1 ; \\
w_{\max }^{s}\left(\times \frac{p_{0} a^{4}}{D}\right)\end{array}$ & $\begin{array}{c}\frac{D_{s} a^{2}}{D}=10 \\
w_{\max }^{s}\left(\times \frac{p_{0} a^{4}}{D}\right)\end{array}$ & $\begin{array}{c}\frac{D_{s} a^{2}}{D}=20 \\
w_{\max }^{s}\left(\times \frac{p_{0} a^{4}}{D}\right)\end{array}$ & $\begin{array}{c}\frac{D_{s} a^{2}}{D}=50 \\
w_{\max }^{(s)}\left(\times \frac{p_{0} a^{4}}{D}\right)\end{array}$ \\
\hline 1.0 & $6.496 \cdot 10^{-2}$ & $28.48 \cdot 10^{-2}$ & $28.48 \cdot 10^{-2}$ & $2.848 \cdot 10^{-2}$ & $1.424 \cdot 10^{-2}$ & $0.5696 \cdot 10^{-2}$ \\
\hline 1.2 & $9.024 \cdot 10^{-2}$ & $34.72 \cdot 10^{-2}$ & $34.720 \cdot 10^{-2}$ & $3.4720 \cdot 10^{-2}$ & $1.7360 \cdot 10^{-2}$ & $0.69440 \cdot 10^{-2}$ \\
\hline 1.4 & $11.280 \cdot 10^{-2}$ & $38.68 \cdot 10^{-2}$ & $38.68 \cdot 10^{-2}$ & $3.868 \cdot 10^{-2}$ & $1.934 \cdot 10^{-2}$ & $0.7736 \cdot 10^{-2}$ \\
\hline 1.6 & $13.280 \cdot 10^{-2}$ & $41.68 \cdot 10^{-2}$ & $41.68 \cdot 10^{-2}$ & $4.168 \cdot 10^{-2}$ & $2.084 \cdot 10^{-2}$ & $0.8336 \cdot 10^{-2}$ \\
\hline 1.8 & $14.896 \cdot 10^{-2}$ & $43.92 \cdot 10^{-2}$ & $43.92 \cdot 10^{-2}$ & $4.392 \cdot 10^{-2}$ & $2.196 \cdot 10^{-2}$ & $0.8784 \cdot 10^{-2}$ \\
\hline 2.0 & $16.208 \cdot 10^{-2}$ & $45.56 \cdot 10^{-2}$ & $45.56 \cdot 10^{-2}$ & $4.556 \cdot 10^{-2}$ & $2.278 \cdot 10^{-2}$ & $0.9112 \cdot 10^{-2}$ \\
\hline 3.0 & $19.568 \cdot 10^{-2}$ & $49.08 \cdot 10^{-2}$ & $49.08 \cdot 10^{-2}$ & $4.9080 \cdot 10^{-2}$ & $2.454 \cdot 10^{-2}$ & $0.9816 \cdot 10^{-2}$ \\
\hline 4.0 & $20.512 \cdot 10^{-2}$ & $49.80 \cdot 10^{-2}$ & $49.80 \cdot 10^{-2}$ & $4.980 \cdot 10^{-2}$ & $2.49 \cdot 10^{-2}$ & $0.9960 \cdot 10^{-2}$ \\
\hline 5.0 & $20.752 \cdot 10^{-2}$ & $49.96 \cdot 10^{-2}$ & $49.96 \cdot 10^{-2}$ & $4.996 \cdot 10^{-2}$ & $2.498 \cdot 10^{-2}$ & $0.9992 \cdot 10^{-2}$ \\
\hline$\infty$ & $20.832 \cdot 10^{-2}$ & $50.00 \cdot 10^{-2}$ & $50.00 \cdot 10^{-2}$ & $5.000 \cdot 10^{-2}$ & $2.500 \cdot 10^{-2}$ & $1.0000 \cdot 10^{-2}$ \\
\hline
\end{tabular}

Table 2 - Convergence characteristics of $w^{f}$ and $w^{s}$ for $b / a=1$

\begin{tabular}{|c|c|c|c|}
\hline$m$ & $n$ & $w_{\max }^{f}\left(\times 10^{-2} \frac{p a^{4}}{D}\right)$ & $w_{\max }^{s}\left(\times 10^{-2} \frac{p a^{4}}{D_{s}}\right)$ \\
\hline 1 & 1 & 6.657 & 32.851 \\
\hline 3 & 1 & 6.568 & 30.661 \\
\hline 1 & 3 & 6.479 & 28.470 \\
\hline 3 & 3 & 6.489 & 28.876 \\
\hline 3 & 5 & 6.487 & 28.748 \\
\hline 5 & 3 & 6.486 & 28.619 \\
\hline 5 & 5 & 6.486 & 28.671 \\
\hline 5 & 7 & 6.486 & 28.646 \\
\hline 7 & 5 & 6.486 & 28.620 \\
\hline 7 & 7 & 6.486 & 28.634 \\
\hline
\end{tabular}

\section{Results and Discussion}

The governing partial differential equation of equilibrium of rectangular isotropic sandwich plate with simply supported edges $(\mathrm{x}= \pm \mathrm{a} ; \mathrm{y}= \pm \mathrm{b})$ given by Equation (1) has been solved to obtain the unknown deflections for the case of uniformly distributed load over the entire plate. Vlasov procedure was adopted to choose the shape functions as the orthogonal eigen functions of vibrating Euler Bernoulli beams as Equations (14) and (15). The Galerkin - Vlasov variational integral was obtained as Equation (18). Simplifications by use of the orthogonality of the eigen basis functions and integrations yielded the solution for the unknown generalized displacement coordinates as Equation (30).

It was observed that the solution for displacements showed there are two displacement components; flexural displacements and shear displacements. For uniform loads, the flexural displacements were obtained as Equation (40) and the shear displacements as Equation (41). The series obtained for the displacements were rapidly convergent and the convergent solutions after five (5) terms of the series for different aspect ratios were calculated and presented in Table 1. The table shows that as the ratio Ds/D increases, the contribution of shear deformation to the overall deformation of the sandwich plate reduces. 
Table 2 illustrates that the expression for flexural component of deflection converges faster than the expression for the shear component. Convergence to the exact flexural component is achieved for $m=n=5$, while that for the shear component is achieved for higher values of $m, n$. The Galerkin Vlasov solutions obtained in this study were in exact agreement with solutions obtained for simply supported isotropic sandwich plates by Plantema, (1966) who used a Navier series method.

\section{Conclusions}

The Galerkin-Vlasov method has been successfully used to solve the governing partial differential equations of isotropic sandwich plates with simply supported edges $(x= \pm a ; y= \pm b)$ under uniformly distributed load.
The solution gave exact solution for the deflection as a rapidly converging double trigonometric (cosine) series of infinite terms.

The deflection $w(x, y)$ was found to be made up of a flexural component $w^{(f)}(x, y)$ and a shear component $w_{(x, y)}^{(s)}$.

The contribution of the shear deformation to the total (resultant) deformation reduces as the ratio $D_{s} / D$ increases.

This paper will hopefully enhance our understanding of the deflection behaviour of simply supported isotropic sandwich plates under uniformly distributed load.

\title{
References
}

1. Allen, H.G. (1969). Analysis and Design of Structural Sandwich Panels. Pergamon Press, Oxford.

2. Balken, D., Azar, O., Turkmen, H. S., \& Mecitoglu, Z. (2010). Transient response of a laminated sandwich plate with viscoelastic core subjected to air blast: Theory and experiment Structures under shock and impact. XI 113 WIT Transactions on The Built Environment, Vol. 113, doi.10.2495/sui00101.

3. Magnucka, E., et al. (2013). Approximate solutions of equilibrium equations of sandwich circular plate. AIP Conference Proceedings, Vol. 1558, Issue 1(2352), doi: 10.1063/1.48260 13.

4. Kinh, H. H. (1972). Analysis of Three Dimensional Orthotropic Sandwich Plate Structures by Finite Element Method. Ph.D. thesis, University Montreal.

5. Kormaniková, E., \& Mamuziċ, I. (2011). Shear Deformation Laminate theory used for sandwiches. Metabk, 50(3), pp. $193-196$.

6. Boen, L.-D. (1965). Theory of Bending of Multilayer Sandwich Plates. Ph.D. thesis, Oklahoma State University.

7. Plantema, F. J. (1966). Sandwich Construction (The Bending and Buckling of Sandwich Beams, Plates and Shells). John Wiley \& Sons, New York.

8. Achilles, P. (1998). Design of sandwich structures. Ph.D. thesis, Cambridge University.

9. Raville, M. E. (1955). Deflection and Stresses in a Uniformly loaded, Simply Supported Rectangular Sandwich Plate. FPL Report.

10. Vinson, J. R. (2001). Sandwich Structures. Applied Mechanics Reviews, No. 54(3), pp. 201-214.

11. Wang, C. M. (1995). Deflection of sandwich plates in terms of corresponding Kirchhoff plate solutions. Archive of Applied Mechanics, Vol. 65, Issue 6, 408-414.

\section{Метод Гальоркіна-Власова для аналізу напружено-деформованого стану рівномірно навантаженої ізотропної шаруватої пластини \\ Мама Б. О. ${ }^{1}$, Іке Ч. Ч. ${ }^{2 *}$

\author{
${ }^{1}$ Нігерійський університет, м. Нсукка, 410101, Штат Енугу, Нігерія; \\ 2 Державний університет науки і технології м. Енугу, П.М.Б. 01660, м. Енугу, Нігерія
}

\begin{abstract}
Анотація. У роботі застосовано метод Гальоркіна-Власова для розв'язання диференціальних рівнянь рівноваги ізотропних шаруватих пластин з рівномірно навантаженими шарнірно опертими краями $(x= \pm a$; $y= \pm b$ ). Обрана процедура Власова для визначення функцій форми як ортогональних власних функцій за моделлю Ейлера-Бернуллі для випадку шарнірних опор і рівномірного навантаження. Результуюче рівняння Гальоркіна-Власова розв'язане з метою визначення невідомої функції узагальненої форми. Встановлено, що отримані переміщення є точними рішеннями задачі про вигин ізотропних шаруватих пластин. Виявлено, що переміщення складаються з двох компонентів: згинальної деформації та деформації зсуву.
\end{abstract}

Ключові слова: ізотропна шарувата пластина; метод Гальоркіна-Власова; рівняння рівноваги; ортогональні власні функції; узагальнені параметри. 